\title{
Retraction Note to: Effect of Material Position and Ultrasonic Vibration on Mechanical Behaviour and Microstructure of Friction Stir-Welded AA7075-T651 and AA6061 Dissimilar Joint
}

\author{
Yuvaraj Kunnathur Periyasamy ${ }^{1}$ (D) Ashoka Varthanan Perumal ${ }^{1}$. \\ Darshan Rajasekaran ${ }^{1}$
}

Published online: 18 October 2019

(C) The Indian Institute of Metals - IIM 2019

\section{Retraction Note to: \\ Trans Indian Inst Met (2018) 71(10):2575-2591 https://doi.org/10.1007/s12666-018-1389-6}

The Editor-in-Chief has retracted this article [1] because the eight cross-sectional macrographs shown in Table 3 are identical with cross-sectional macrographs that are part of Figure 1 in the article by Reza-E-Rabby et al. [2] which presents the results of a study using different tools and welding parameters. The data reported in this article are therefore unreliable. Darshan Rajesekaran and Yuvaraj Kunnathur Periyasamy do not agree with this retraction; Ashoka Varthanan Perumal has not replied to correspondence about this retraction.

\section{References}

1. Kunnathur Periyasamy Y, Perumal A V, and Rajasekaran D, Trans Indian Inst Met 71 (2018) 2575. https://doi.org/10.1007/s12666018-1389-6

2. Reza-E-Rabby Md, Tang W, and Reynolds A P, Sci Technol Weld Join 20 (2015) 425. https://doi.org/10.1179/1362171815y.00000 00036

Publisher's Note Springer Nature remains neutral with regard to jurisdictional claims in published maps and institutional affiliations.

The original article can be found online at https://doi.org/10.1007/s12666-018-1389-6.

Yuvaraj Kunnathur Periyasamy cadyuva94@gmail.com

Ashoka Varthanan Perumal ashokavarthanan@skcet.ac.in

Darshan Rajasekaran darshanraj1701@gmail.com

1 Department of Mechanical Engineering, Sri Krishna College of Engineering and Technology, Coimbatore, India 